OPEN ACCESS

Edited by:

Cynthia B. Silveira,

University of Miami, United States

Reviewed by:

Shaili Johri,

Stanford University, United States

Dita Cahyani,

Yayasan Biodiversitas Indonesia (BIONESIA), Indonesia

*Correspondence:

Gabby N. Ahmadia

gabby.ahmadia@wwfus.org

Samantha H. Cheng

scheng@amnh.org

Specialty section:

This article was submitted to

Coral Reef Research,

a section of the journal

Frontiers in Marine Science

Received: 26 June 2021

Accepted: 26 August 2021

Published: 29 September 2021

Citation

Ahmadia GN, Cheng SH, Andradi-Brown DA, Baez SK,

Barnes MD, Bennett NJ,

Campbell SJ, Darling ES, Estradivari,

Gill D, Gress E, Gurney GG,

Horigue V, Jakub R, Kennedy EV,

Mahajan SL, Mangubhai S,

Matsuda SB, Muthiga NA,

Navarro MO, Santodomingo $N$, Vallès $H$, Veverka $L$, Villagomez $A$,

Wenger AS and Wosu A (2021)

Limited Progress in Improving Gender and Geographic Representation

in Coral Reef Science.

Front. Mar. Sci. 8:731037.

doi: 10.3389/fmars.2021.731037

\section{Limited Progress in Improving Gender and Geographic Representation in Coral Reef Science}

\author{
Gabby N. Ahmadia" ${ }^{1 *}$, Samantha H. Cheng ${ }^{2 *}$, Dominic A. Andradi-Brown', \\ Stacy K. Baez ${ }^{3}$, Megan D. Barnes ${ }^{4}$, Nathan J. Bennett ${ }^{5}$, Stuart J. Campbell', \\ Emily S. Darling 7,8, Estradivari ${ }^{9,10}$, David Gill ${ }^{11}$, Erika Gress ${ }^{12}$, Georgina G. Gurney ${ }^{12}$, \\ Vera Horigue ${ }^{13,14,15}$, Raymond Jakub ${ }^{6}$, Emma V. Kennedy ${ }^{16}$, Shauna L. Mahajan ${ }^{17}$, \\ Sangeeta Mangubhai ${ }^{18}$, Shayle B. Matsuda ${ }^{19}$, Nyawira A. Muthiga ${ }^{20}$, \\ Michael O. Navarro ${ }^{21}$, Nadia Santodomingo ${ }^{22,23}$, Henri Vallès ${ }^{24}$, Laura Veverka1, \\ Angelo Villagomez ${ }^{3}$, Amelia S. Wenger ${ }^{7,25}$ and Adaoma Wosu ${ }^{26}$
}

${ }^{1}$ Oceans Conservation, World Wildlife Fund, Washington, DC, United States, ${ }^{2}$ Center for Biodiversity and Conservation, American Museum of Natural History, New York, NY, United States, ${ }^{3}$ The Pew Charitable Trusts, Washington, DC, United States, ${ }^{4}$ Centre for Environmental Economic and Policy, School of Agriculture and Environment, The University of Western Australia, Perth, WA, Australia, ${ }^{5}$ The Peopled Seas Initiative, Vancouver, BC, Canada, ${ }^{6}$ Rare Indonesia, Kota Bogor, Indonesia, ${ }^{7}$ Marine Program, Wildlife Conservation Society, Bronx, NY, United States, ${ }^{8}$ Department of Ecology and Evolutionary Biology, University of Toronto, Toronto, ON, Canada, ${ }^{9}$ Leibniz Center for Tropical Marine Research (ZMT), Bremen, Germany, ${ }^{10}$ Marine Ecology Department, Faculty of Biology and Chemistry (FB2), University of Bremen, Bremen, Germany, ${ }^{11}$ Duke University Marine Laboratory, Nicholas School of the Environment, Duke University, Beaufort, NC, United States, ${ }^{12}$ Australian Research Council Centre of Excellence for Coral Reef Studies, James Cook University, Townsville, QLD, Australia, ${ }^{13}$ Department of Earth and Environmental Sciences, Macquarie University, Sydney, NSW, Australia, ${ }^{14}$ Western Indian Ocean Marine Science Association, Zanzibar, Tanzania, ${ }^{15}$ University of the Philippines - Marine Science Institute, Quezon City, Philippines, ${ }^{16}$ Australian Institute of Marine Science, Townsville, QLD, Australia, ${ }^{17} \mathrm{Global}$ Science, World Wildlife Fund, Washington, DC, United States, ${ }^{18}$ Fiji Country Program, Wildlife Conservation Society, Suva, Fiji, ${ }^{19}$ Hawai'i Institute of Marine Biology, University of Hawai'i at Mānoa, Kāne'ohe, HI, United States, ${ }^{20}$ Marine Program, Wildlife Conservation Society, Mombasa, Kenya, ${ }^{21}$ Department of Natural Sciences, University of Alaska Southeast, Juneau, AK, United States, ${ }^{22}$ Natural History Museum, London, United Kingdom, ${ }^{23}$ Faculté des Géosciences et de l'Environnment, Université de Lausanne, Lausanne, Switzerland, ${ }^{24}$ Department of Biological and Chemical Sciences, The University of the West Indies at Cave Hill, Bridgetown, Barbados, ${ }^{25}$ Centre for Biodiversity and Conservation Science, University of Queensland, St. Lucia, QLD, Australia, ${ }^{26}$ The Landscapes and Livelihoods Group, Edinburgh, United Kingdom

Despite increasing recognition of the need for more diverse and equitable representation in the sciences, it is unclear whether measurable progress has been made. Here, we examine trends in authorship in coral reef science from 1,677 articles published over the past 16 years (2003-2018) and find that while representation of authors that are women (from 18 to 33\%) and from non-OECD nations (from 4 to 13\%) have increased over time, progress is slow in achieving more equitable representation. For example, at the current rate, it would take over two decades for female representation to reach $50 \%$. Given that there are more coral reef non-OECD countries, at the current rate, truly equitable representation of non-OECD countries would take even longer. OECD nations also continue to dominate authorship contributions in coral reef science (89\%), in research conducted in both OECD (63\%) and non-OECD nations (68\%). We identify systemic issues that remain prevalent in coral reef science (i.e., parachute science, gender bias) that likely contribute to observed trends. We provide recommendations to address systemic biases in research to foster a more inclusive global science community. 


\begin{abstract}
Adoption of these recommendations will lead to more creative, innovative, and impactful scientific approaches urgently needed for coral reefs and contribute to environmental justice efforts.
\end{abstract}

Keywords: coral reef science, gender, equity, inclusion, representation, diversity

\section{INTRODUCTION}

Sustainability and conservation challenges in the twenty-first century are complex and systemic, requiring increasingly interdisciplinary and diverse perspectives to address them. Numerous global environmental commitments, including the United Nations Decade of Ocean Science for Sustainable Development, call for diverse partnerships to achieve the 2030 Agenda for Sustainable Development. Increasing the diversity of voices in ocean science and sustainability practice is critical, as the consequences of inaction and/or misguided policies fall most heavily on countries where biodiversity and resource dependency are highest (Selig et al., 2018; OECD, 2020). In addition, those whose voices often go unheard bear a significant portion of this burden (Stuchtey et al., 2020).

Excellence in science is inextricably bound to improved diversity, equity, and inclusion (DEI) in the research community. There is clear evidence demonstrating how equity and diversity in science fosters new ideas and progress in research (Freeman and Huang, 2015; Tulloch, 2020). A lack of diversity in research groups is partly due to a long history of gatekeeping, colonization, and direct harm done to individuals and groups globally, and is consequently, a missed opportunity to collectively harness the perspectives and ways of knowing held by diverse experts to advance scientific innovation and potential impact. Scientific research contributes to shaping societal priorities, policy, and solving global challenges such as climate change, environmental degradation, and poverty; one way this knowledge is shared is through scientific papers, and these recordkeepers continue to remain the currency of our fields. Authorship drives these priorities and can act to amplify the voices of a few. If this chorus continues to be exclusive, solutions produced may not be relevant nor appropriate for the realities that different individuals, communities, and nations experience (Hofstra et al., 2020), and at worst, further exacerbate existing inequities and cause undue harm (Eisenstein, 2018).

Diverse representation continues to fall short in the global science community as research continues to be dominated by "Western" countries and men. Studies demonstrate that gender inequality persists at all scales, from the composition of research institutions and research groups to grant recipients and leadership positions (Arismendi and Penaluna, 2016). For example, in the United States, women are vastly underrepresented amongst academic faculty, receive less grant funding (Vernos, 2013), publish fewer scientific articles (Martin, 2012; Conti and Visentin, 2015), have shorter publishing careers, lower rates of retention (Huang et al., 2020), and receive fewer citations of their work (Bray, 2020). Manuscripts where women listed as first authors in fisheries science journals are significantly (4\%) less likely to be accepted than men listed as first authors, reflecting biases in the American Fisheries Society's peer review process (Handley et al., 2015). These inequities are compounded for women who are LGBTQ+, disabled, Black, Indigenous, or women of color in the US (Arismendi and Penaluna, 2016). Importantly, structures of power and sociopolitical factors shape the disparate and myriad challenges experienced by women globally. There are also shortfalls in geographic diversity as scientists in countries with developing economies remain vastly underrepresented on the global research stage (Larivière et al., 2013; Melles et al., 2019), specifically those nations that are not members of the Organization for Economic Co-operation and Development (OECD (Adenle et al., 2015)). This is further exacerbated by phenomenon of "parachute science" or "helicopter science," a common practice in many non-OECD nationswhere in-country research (usually in non-OECD nations) is conducted by teams nearly exclusively comprised of external scientists (usually from OECD nations) often with little input, collaboration, or recognition of local scientists (de Vos, 2020; Stefanoudis et al., 2021).

Here, we consider the representation of scientists working in one of the world's most biodiverse and threatened ecosystems, tropical coral reefs. Researchers from non-OECD nations and women researchers globally are disproportionately underrepresented in coral reef research/literature. Many coastal communities live alongside coral reefs, which provide a wealth of social benefits including food security, income, coastal protection, and cultural practice, as well as indirectly supporting coastal livelihoods and sectors through tourism (Spalding et al., 2016). The effects of climate change on global coral reefs are only worsening, and conservation and management strategies will require more collaborative, innovative, science-based solutions, in partnership with local researchers, and consideration of the needs of coastal communities (e.g., Fisher et al., 2011). While there are signs of progress toward increasing more equitable representation of scientists, it is unclear if the current pace and level of effort will deliver timely change.

Calls to increase diversity typically refer to broadening the representation of gender, race/ethnicity, disabilities, religion, economic status, geographic place, knowledge systems, and much more; all are essential for pursuing creative, innovative, inclusive research, and perhaps more importantly, building equitable societies. Identities are multi-dimensional, and intersectionality further modulates individual and systemic exclusion. Here, we focus on gender and geographic representation; we recognize the constraints of the data available and the methodological limitations of categorization (which we discuss below). This is an initial step aimed at assessing progress and better defining actionable solutions that may broaden scientific excellence, opportunity, and equity in coral reef research. 
We investigated trends in authorship with respect to gender (limited to men and women) and geographic location of organizational affiliation (which we categorized as OECD or nonOECD member nations; see Supplementary Methods). Using data on authorship of coral reef science published over 16 years (2003-2018), we asked:

(1) How has representation in authorship changed with respect to the geographic location of authors' institutional affiliation?

(2) How has geographic representation of authors (in terms of affiliation and research) changed?

(3) How have collaborative ties among authors affiliated with organizations in OECD and non-OECD nations changed?

(4) Has the proportion of men and women authors changed?

\section{MATERIALS AND METHODS}

We utilized a systematic search strategy for identifying and collating coral reef research publications in 10 leading international journals in coral reef science [Conservation Letters, Proceedings of the National Academy of Sciences (PNAS), Proceedings of the Royal Society B, Coral Reefs, PlosOne, Marine Policy, Marine Biology, Frontiers in Marine Science, Nature, and Science]. Although the volume of research publications in international, English-language, peer-reviewed journals may not be indicative of coral reef research and effort on the ground (Nuñez and Amano, 2021), examining dimensions of diversity in 10 leading international journals can illustrate how the composition of scientific contributors has changed over time. We chose these journals because they all focus on or feature coral reef research and are highly regarded in both the marine science and general conservation and environmental science arenas. These 10 journals also account for $10 \%$ of all articles containing "coral reef" in the title, abstract, and/or keywords indexed in Web of Science and have high impact factors either in physical and biological sciences generally or for marine science topic journals. Given their regard and popularity, these journals represent good choices analyzing changes in representation over time.

We used a Boolean search strategy (i.e., joining key terms with Boolean logic operators) in Web of Science (all databases) to identify potentially relevant articles published in these journals between 2003 and 2018. The search was executed on March 1, 2019 using the search term "coral reef" for the first 8 journals listed above. A second search was executed in Web of Science on April 8, 2019 with the same search term, but limited to articles from the journals Nature and Science.

The resulting articles were divided amongst the author team and coding was conducted using an priori protocol. The following meta-data field were derived from Web of Science records: author name, institutional affiliation, country of affiliation, title of study, abstract, publication year, DOI, times cited, journal name.

Author names were cleaned manually by looking up each paper and author information to confirm spelling, initials, etc. ... to determine unique authors. A team of reviewers worked collaboratively to code information about authors and studies. The following information on authors was coded for each author listed on a paper: identified gender, and whether the author was based in the country of study. The following information was coded from each article: country (countries) of study, study region, whether the study took place in a territory of another sovereign nation or a disputed territory, study type, marine realm of study.

Study country: Based on the abstract and/or full text, reviewers coded what country the study took place in. For studies in more than five countries, studies were coded for a study region instead. For overseas territories, study country was coded as the sovereign nation and territories were indicated in a distinct column.

Study region: Region where study took place, also includes global studies.

Study type: Studies could be coded for multiple types including fieldwork, modeling, synthesis, laboratory, and desk studies.

Marine realm: Marine realm (using the Marine Ecoregions of the World typology) of study.

Is the author based in the country of study?: Based on the author's institutional affiliation for each study, reviewers coded this field as "yes," "no," or "NA" depending on whether the country of affiliation is same as the country of study.

Order of authors (e.g., first, last, etc. ...): This was coded using a custom R script based on Web of Science records.

\section{Gender Identity}

The following decision process was used to determine author gender: (1) Each author was searched in Google. (2). Based on their online profiles, reviewers made a determination on gender based on stated pronouns. In the absence of pronouns, reviewers based their decision on their own personal knowledge and/or consultation with others on the author team who may have known an author personally. (3). If no determination could be made, gender was entered as "undetermined." For authors that could not be located online, gender was entered as "not found." We recognize that the method of determining gender is imprecise and may underrepresent individuals who identify as non-binary (linking to issues highlighted in the discussion). We recognize that gender exists on a spectrum and to the best extent of our ability, categorized gender based on publicly available information from stated pronouns, personal web pages, social media accounts, and personal communications. Our aim with this study is to highlight gender representation issues in coral reef science, not to provide a precise tabulation of gender composition. Thus, the gender categories we code for are a heuristic estimate of gender in the field.

\section{Geographic Groupings}

In this analysis, we use institutional affiliation as a proxy for geographic diversity and as a way to understand national and international collaboration in the study of coral reefs. We recognize that individuals who may identify ethnically, racially, and/or in terms of nationality may be affiliated with 
institutions that are in other countries/regions, thus, this is a heuristic estimate of diversity. We examined how often authors were involved in national vs. international collaborations, how often "in-house" research occurs in different countries (national authors leading/contributing to studies in that country), and how often authors from different regions did research in other regions.

Throughout this study, we aim to examine geographic representation of authors-particularly taking into account the impact of historical legacies and social factors (e.g., colonialism, capitalist markets and expansion, and geopolitical relations) on the evolution of scientific disciplines, research infrastructure, and scientific collaboration. Comparing patterns between countries who have benefitted from past history and current conditions and those who have not, can shed light on how far coral reef science has progressed in terms of improving diversity, equity, and inclusion. In order to make these types of comparisons, we needed to categorize and label sets of nations-which in itself, raises its own issues for inclusion and representation. Historically, the way in which nations were categorized was based on economic characteristics - such as income and gross domestic product-which has been widely denounced as an outof-date and one-dimensional metric that does not accurately nor fairly reflect nations. Terminology revolved around developed vs. developing vs. underdeveloped nations, Third World vs. First World, and Global North vs. Global South. All of these groupings have been debated over the years and many have fallen out of use as development actors increasingly recognize and acknowledge the problematic nature of these often externally assigned labels.

Within these analyses, we opted to grouped nations by their OECD membership (as of 2021) as a way to characterize national economies, as opposed to externally defined income groups or development index which are grounded in problematic and monolithic metrics and contexts (Fantom et al., 2016). While self-selected, OECD members generally have high income economies and high human development index, representing nations that have historically held greater resources for scientific research. Many OECD members have tropical reefs within their waters (incl. territories) (e.g., Australia, Colombia, France, Israel, Japan, Mexico, Netherlands, United Kingdom, United States). While OECD membership is not perfect, it is generally a self-selected process where countries choose to apply for membership and thus, is to a degree, a more inclusive process for countries to self-identify. We used 2021 OECD membership to categorize countries, and categorized territories, protectorates, and collectivities of OECD countries as OECD (e.g., French Polynesia, as an overseas collectivity of France).

However, there are still issues that arise when grappling with geopolitical labels (e.g., Latin America, East Asia and the Pacific) that are useful for describing groups of countries but often reflect Western-driven groupings. We adopted the World Bank region categories to examine authorship patterns for this paper, however, we also want to recognize that there are standing issues with these categorizations and they should not be taken as a standard of practice.

\section{Statistical Analysis}

We examined author contributions by calculating the proportion of publication output contributed by each identified author (gender and geography) in a given article. For example, if a paper had nine authors, of which eight authors identified to gender category, each identified author was assigned an equal share of authorship (an eighth). These fractions were then aggregated by gender and geographic affiliation to calculate author contributions. Summary statistics were calculated in R and the data cleaning and analysis scripts are available on github. ${ }^{1}$

We used descriptive network analysis to examine patterns in co-authorship between authors affiliated with OECD vs. nonOECD nations over time. We created undirected graphs (parallel edges) of co-authorship for each year in our analysis using the igraph package (Csardi and Nepusz, 2006) in R. Each node represents a unique combination of author and affiliation, while the edges represent connections to co-authors. Authors who had multiple affiliations across different countries listed on a single article were reduced to one affiliation (prioritizing affiliations in non-OECD countries if they had affiliations in both). $7.88 \%$ of the total author pool had more than one affiliation listed on a paper (322 authors across 329 articles), with $31 \%$ of those having an affiliation in both OECD and non-OECD nations (100 authors). We assigned affiliations to OECD nations using the 2021 membership regardless of year of publication. Our designation scheme was balanced, to a degree between OECD vs. non-OECD assignments. We qualitatively describe patterns of collaboration between authors affiliated with institutions in OECD vs. non-OECD nations over time.

\section{RESULTS}

\section{Summary of Papers}

We recovered 1,677 articles authored by 4,485 unique authors with geographic affiliations spanning 95 countries; authors affiliated with institutions in the United States ( $n=1,625, \sim 36 \%)$, Australia ( $n=921, \sim 21 \%$ ), the United Kingdom $(n=257$, $\sim 6 \%)$, France $(n=184, \sim 4 \%)$, Germany $(n=165, \sim 4 \%)$, Japan $(n=163, \sim 4 \%)$, Canada $(n=146, \sim 3 \%)$, and Brazil $(n=137$, $\sim 3 \%)$ accounted for $>70 \%(n=3,598)$ of authors. Institutional affiliations in the United States and Australia make up over half the dataset and had the largest total contribution to published articles ( $n=\sim 553$ and $\sim 541$ articles, respectively), thus these two countries are separated out from the rest of their regional group in subsequent analysis for improved clarity. Of the next top 20 contributing nations to coral reef science publication, only five were non-OECD (Brazil, Indonesia, Panama, Philippines, Saudi Arabia) (Supplementary Figure 1). Over 16 years (20032018), the contribution of authors per country to published articles has been variable, with some countries increasing steadily (e.g., Australia, Canada, United Kingdom, United States) and others have fluctuated (e.g., Indonesia, Mexico, Panama, Panama, Netherlands) (Supplementary Figure 1). We were able to associate gender with $\sim 96 \%$ of authors and were unable to locate information for 46 authors. While no authors who explicitly identified as non-binary were identified, we recognize that not all non-binary authors or authors with other gender identities may identify publicly (see Supplementary Methods).

\footnotetext{
${ }^{1}$ https://github.com/scheng87/coralreef
} 


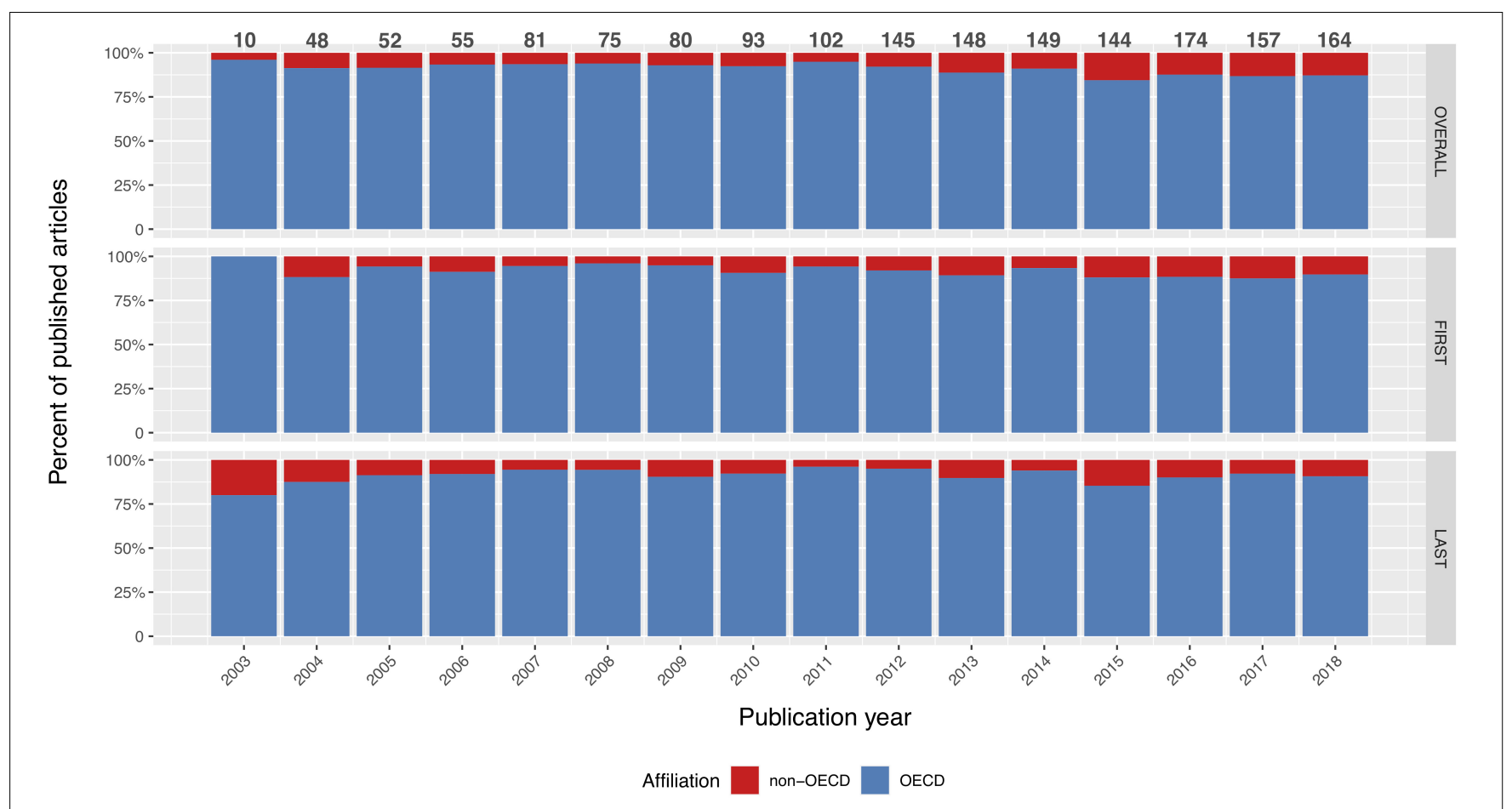

FIGURE 1 | Change in overall individual contribution of authors affiliated with institutions in non-OECD vs. OECD nations. Published articles over time (top panel) disaggregated by first (middle panel) and last author (bottom panel) position for articles with more than one author. For authors with more than one institutional affiliation, their non-OECD affiliation is used in this analysis. Numbers at the top of each bar indicate the total number of articles published that year.

\section{Geographic Trends}

The majority of articles described field-based studies $(n=1,068)$ and generally described research conducted in or concerning the Central Indo-Pacific ( $n=690$ articles) and the Tropical Atlantic (e.g., Caribbean) $(n=332)$. In comparison, there were considerably fewer studies in the Eastern $(n=200)$ and Western $(n=147)$ Indo-Pacific (Supplementary Figure 2). Over the 16 year time series, overall authorship contribution from authors affiliated with institutions in non-OECD countries grew from $\sim 4$ to $\sim 13 \%$ (Figure 1). In general, authors across all types of studies were more likely to affiliate with institutions in OECD nations ( $\sim 90 \%$ proportion of authorship). Of the articles examined, $1,329(\sim 80 \%)$ articles were entirely composed of all OECDaffiliated authors, while 64 articles $(\sim 4 \%)$ had entirely nonOECD affiliated author teams. Generally, in authorship order the first author represents the researcher who led the work while the last author represents the "senior" author, often the head of a lab/research group. We find that representation of nonOECD affiliated authors have remained low over the study period across first and last authors, reflecting trends in overall authorship contribution $(\sim 12 \%$ first authors, $8 \%$ last authors, and $11 \%$ of authors overall contributing to papers in 2018).

Considering author affiliations compiled into World Bank regions (World Bank, 2021), we found that scientists based in Australia, Europe, and North America typically work across multiple regions, including East Asia and the Pacific, Latin America, and the Caribbean, while researchers from other regions tend to publish work related to the region of their affiliation (Figure 2). For example, research conducted in reefs in East Asia and the Pacific are dominated by authors based in Australia, Europe, and the United States $(\sim 75 \%$ of author contributions) with around 25\% contribution from authors affiliated within the region. In contrast, while there is a similar volume of research conducted in Australia, the majority of contributing authors are affiliated with Australian institutions, with just $\sim 5 \%$ from East Asia and the Pacific.

In general, author teams were more likely to be composed of entirely in-country ( $n=649$ articles, $42 \%$ of total articles) or entirely out-of-country researchers $(n=374$ articles, $24 \%$ of total articles). Only a third of articles $(n=484)$ examined had mixed teams of local authors publishing with authors from outside the country where the fieldwork was conducted. Of the mixed collaboration teams that conducted research in nonOECD nations ( $n=373$ articles), on average, 50\% of the authors had an affiliation within the country of study. Research in OECD nations was predominantly conducted by in-country authors (e.g., $63 \%$ of total studies in OECD nations), while research in non-OECD nations was predominantly conducted by authors from outside of those nations (68\%) (Figure 3). For example, researchers affiliated with American institutions made up 88\% of authorship contributions to research conducted on U.S. coral reefs $(n=226$ articles). Conversely, for research conducted in Indonesia ( $n=66$ articles), a region with significantly greater reef area, only $25 \%$ of authorship contribution was from researchers affiliated with Indonesian institutions. While contribution to published research conducted in non-OECD 


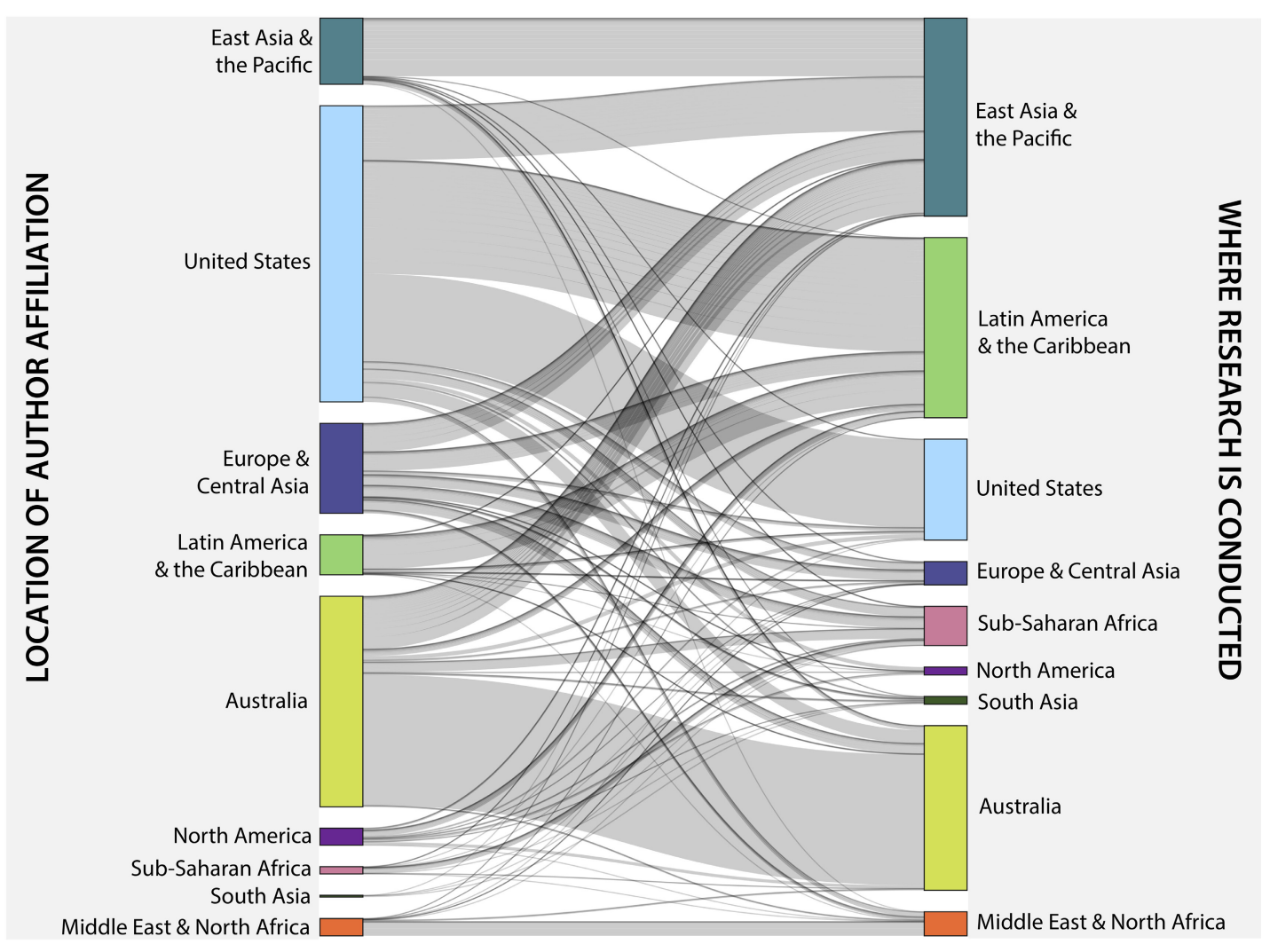

FIGURE 2 | Connections between author affiliations (left) and the location of conducted research (right). Each connection represents a unique article; authors may be represented more than once across multiple institutions and articles over time. Groupings follow World Bank regions except for the United States shown separately from North America (which here represents Canada, Bermuda) and Australia shown separately from East Asia and the Pacific because of the large number of publications from these two nations.

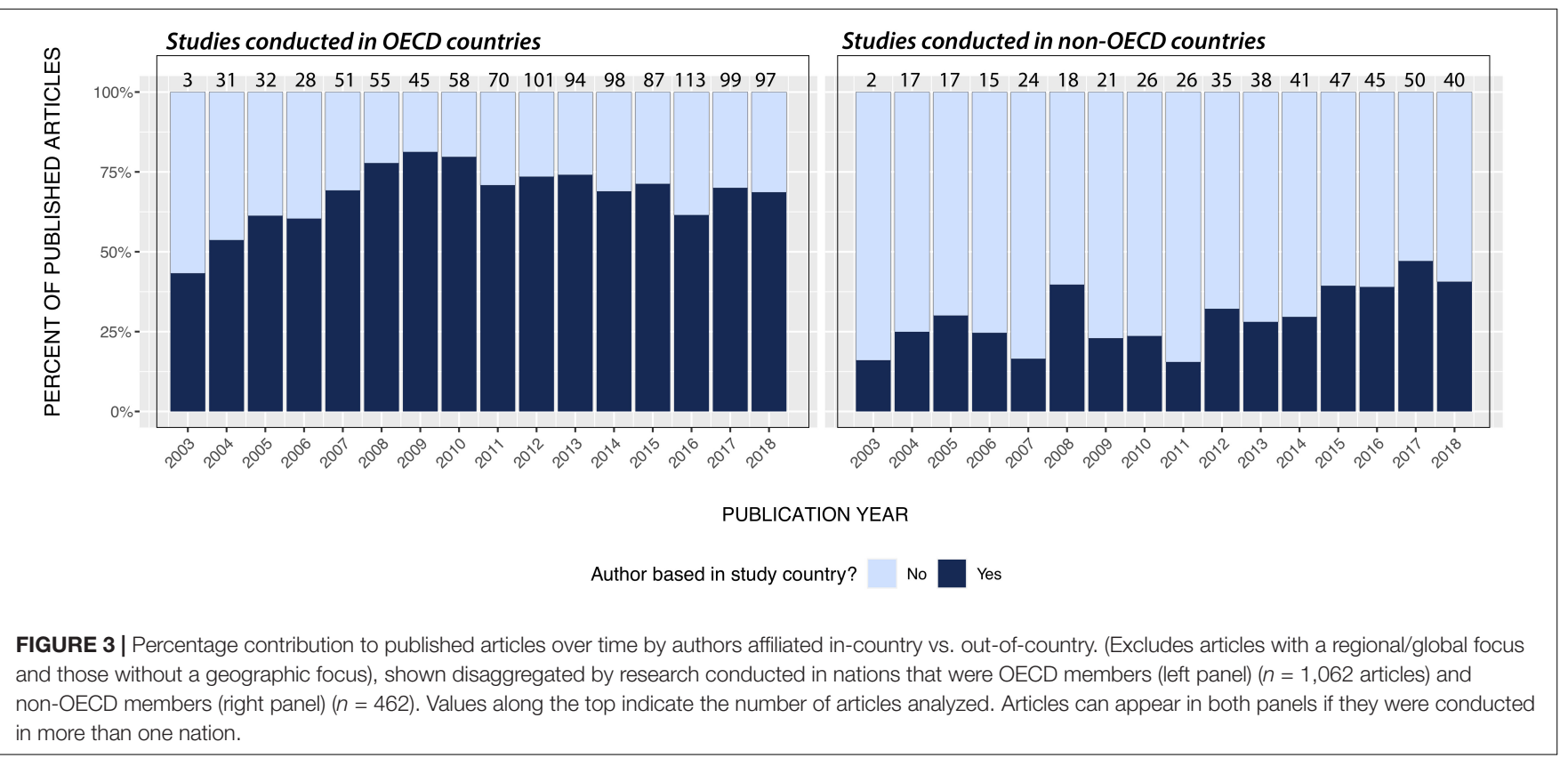




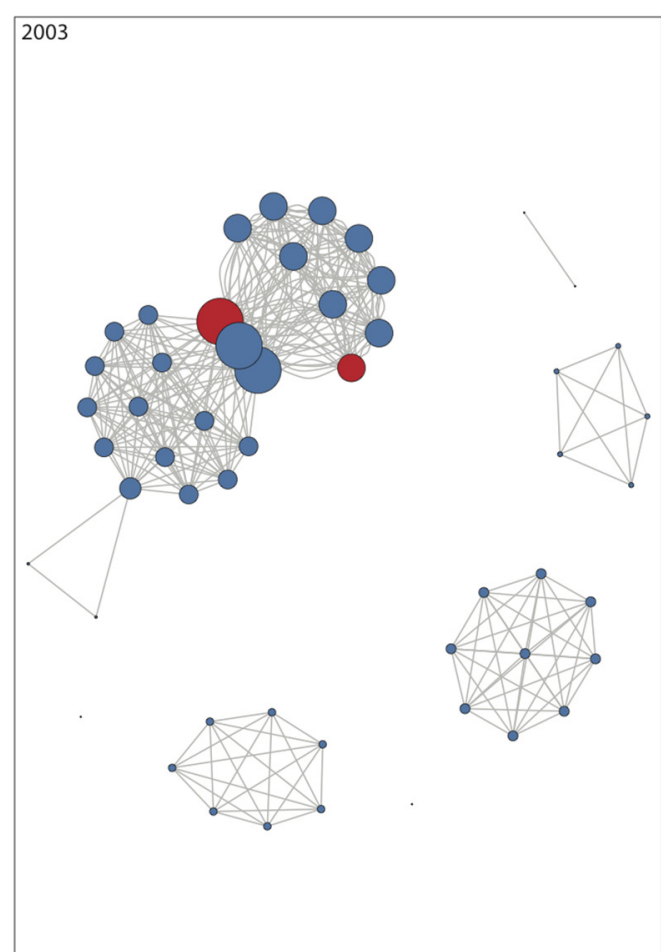

Author affiliation

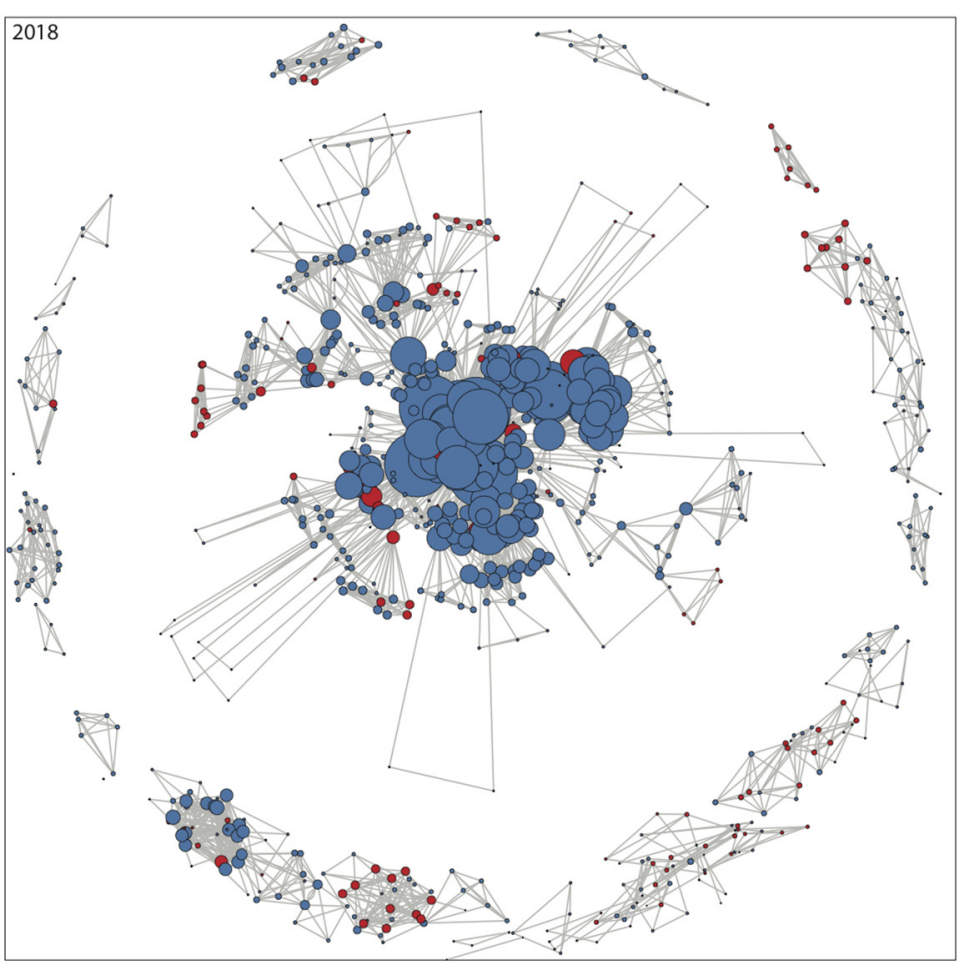

non-OECD OECD

FIGURE 4 | Networks of co-authors compared between articles published in 2003 and 2018 disaggregated by affiliation of authors (OECD vs. non-OECD). Each node represents a unique author/affiliation combination while each edge represents collaboration between authors on a publication; the size of the node indicates the number of articles that author contributed to that year. The length of the edge indicates how close authors are to each other (the more co-authored publications, the closer the authors). Each plot displays the co-authorship networks of all papers published in that year-and thus the clusters in each year are independent from each other-and illustrate annual shifts in collaborative networks. See Supplementary Figure 4 for 2004-2017.

nations by in-country scientists increased over our timeframe (from $\sim 16 \%$ of total contribution in 2003 to $\sim 41 \%$ in 2018 ), this still remains low compared to coral reef studies that occur in OECD nations.

Using network analyses, we considered how scientists are collaborating across OECD and non-OECD nations over the 16 year study period (Figure 4). The majority of articles published in 2018, the last year for which contributions were assessed, were authored by a large but rather geographically disconnected group of individuals who had significant collaborations within their group, but few connections outside of their group. Interestingly, authors outside of the group formed individual groups on their own; however, the network plot (Figure 4) suggests these groups display more inter-group connections potentially forged by individuals working across disciplines or countries who bridged collaborations. Disaggregating by region, we see that most of the co-author teams in 2018 are composed of individuals affiliated with institutions in OECD nations, while groups on the periphery include more researchers affiliated with institutions in non-OECD nations. In comparison with 2003, the relative proportion of authors from institutions in non-OECD nations has increased and there are some more prolific publishers within the center of the network; however, far more are on the periphery (Figure 4).

\section{Gender Trends}

Over the 16 year time series, gender balance of authors in coral reef science (whose gender identity could be inferred) increased from $\sim 18$ to $\sim 33 \%$ contribution by female authors from 2003 to 2018 (Figure 5), fluctuating between 25 and 35\%. In general, authors across all types of studies were more likely to be men ( $\sim 70-80 \%$ proportion of authorship). Of the articles examined, $525(\sim 31 \%)$ articles were composed of entirely male authors, while 80 articles $(\sim 5 \%)$ had entirely female authors. In terms of authorship order, we find that while gender representation may appear to be moving closer toward an equal balance in first authors (36\% women first authors overall and 40\% in 2018), last authors remain dominated by men (77\% overall and $80 \%$ in 2018) (Figure 5).

The pattern of gender representation was similar across the most well-represented geographies of affiliation. In the United States and Australia, women authors (33 and 29\% of affiliated authors, respectively) represented a pattern that is reflected across the majority of the next top 20 contributing 


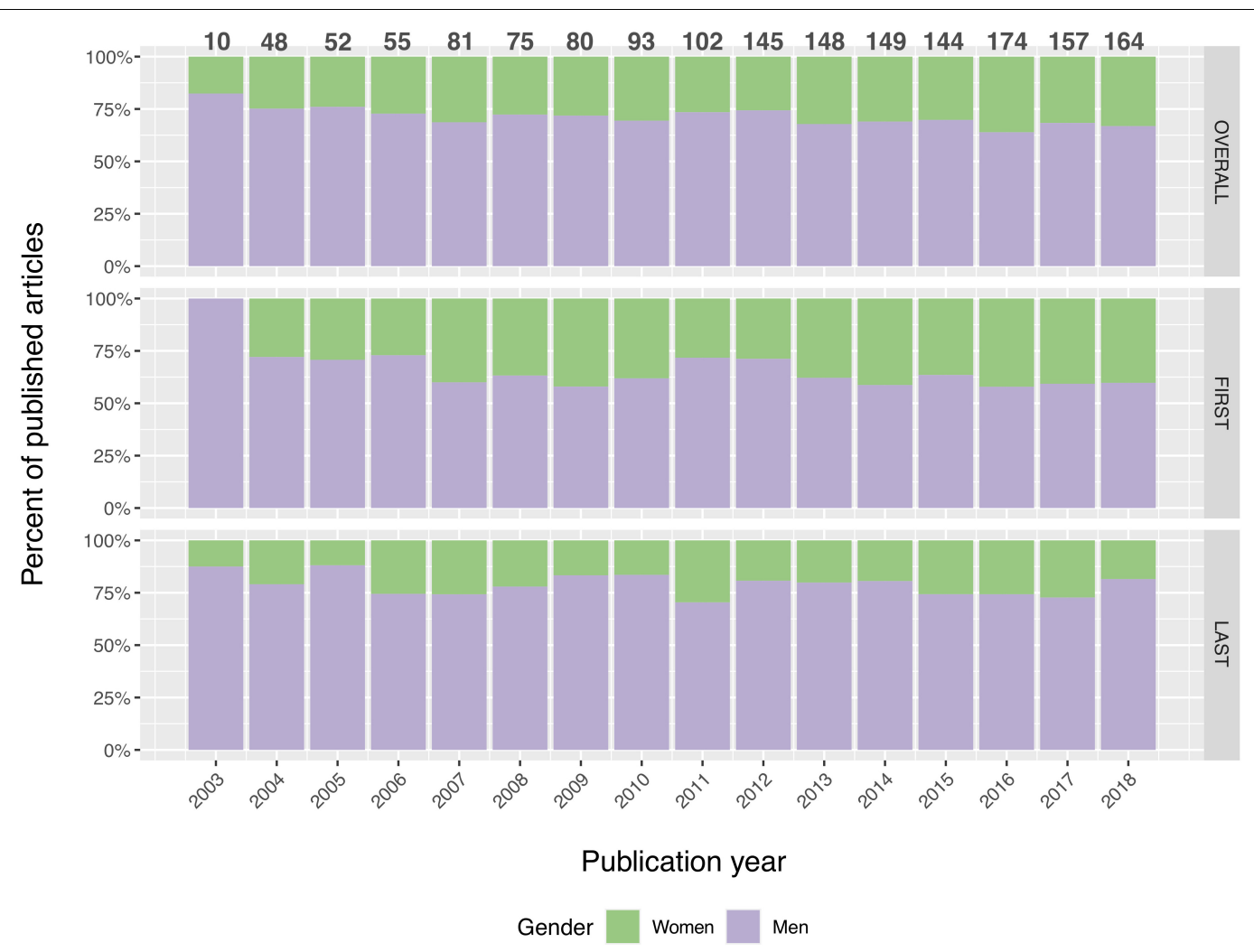

FIGURE 5 | Change in overall individual contribution of genders to published articles over time (top panel) disaggregated by first (middle panel) and last author (bottom panel) position for articles with more than one author. Numbers at the top of each bar indicate the total number of articles published that year.

nations (Supplementary Figure 3). Some countries (e.g., Israel, Japan, Saudi Arabia) were mostly represented by men (but overall low representation in terms of affiliated author geography). In terms of author position, in the United States of America and Australia there were more women first authors $(37 \%, 36 \%)$ than last authors $(25.7 \%$, 20\%). Examining trends in gender representation in the other top producing nations, we observe that the patterns are much more varied (Supplementary Figure 3). For OECD nations, only Canada, Mexico, the Netherlands, and the United Kingdom had more than $25 \%$ women as last authors on papers to which their authors contributed. For top contributing non-OECD nations, Brazil and Philippines had near equal representation of men and women as first authors. However, for these nations, authors who were women were barely represented, if at all, as last authors (Supplementary Figure 3).

\section{DISCUSSION}

There have been numerous calls to improve equity in representation in global fora that frame issues, determine priorities, and present solutions toward sustainability and conservation (Ahmadia, 2018; Brown et al., 2019). Similarly, there should be equitable representation of diverse voices generating knowledge that informs those priorities (Purdy, 2015).
Coral reefs are among the most vulnerable marine ecosystems to climate change and human impacts, and research must reflect and harness the collective global diversity and expertise to grapple with the massive conservation challenges that these ecosystems face in the twenty-first century (e.g., Fisher et al., 2011; Bennett, 2018). Despite decades of awareness and calls for change from higher education institutions to global platforms, we find that substantial gender and geographical diversity gaps remain. Our study examines 10 highly popular and high impact journals that feature or focus on marine science-thus, our analysis is somewhat limited to understanding representation in these types of journals. Examining whether women and local scientists are better represented in "lower" popularity or impact journals, or national/regional journals is beyond the scope of this work, however, is worthwhile pursuing for future work. Nonetheless, our study shows that while representation in terms of author contributions to published articles in coral reef science papers showed initial improvement, trends in representation have remained stagnant over the past 10-13 years. This continued disparity in geographic and gender representation in coral reef research is just one symptom of multiple, interacting systemic issues (Table 1) in scientific research and wider society that limit the inclusion of many underrepresented groups (Chaudhury and Colla, 2020).

Increasing geographical representation in coral reef science leadership and research clearly remains a challenge, given 
TABLE 1 | Systemic issues of neocolonial/globalization research practices that contribute to lack of gender and geographic diversity in coral reef science.

\begin{tabular}{ll}
\hline Issue & Description \\
\hline Hidden labor & $\begin{array}{l}\text { Researchers left out of authorship either intentionally or } \\
\text { because of different perceptions as to "what counts" to be } \\
\text { listed as an author. }\end{array}$ \\
& \\
Biases and stereotypes & $\begin{array}{l}\text { Researchers from underrepresented groups are often viewed } \\
\text { less favorably (Handley et al., 2015). Perceptions of quality and } \\
\text { merit of research ability and output differs between men and } \\
\text { women. Processes and/or outputs generated using western } \\
\text { scientific methods are perceived as being more credible } \\
\text { compared with local and Indigenous knowledge. }\end{array}$
\end{tabular}

Inequality in research funding and opportunities

Non-inclusive publication system

Lack of infrastructure or support for researchers in nonOECD countries

Barriers that inhibit career growth and development for women in the workplace
There is more research funding for wealthier countries both for domestic and international research (Miller et al., 2013; Meijaard et al., 2015; Waldron et al., 2017). Also, the research funding for international researchers from OECD nations is often more flexible, compared to research grants more defined in scope available to non-OECD nations.

Structures and process in the publication system exclude researchers including: (1) English as the primary language in international journals and translators unaffordable; (2) review process can be biased against underrepresented groups; (3) invited reviews - often target men and authors from OECD nations; and (4) cost of publishing may be inhibitive for scientists from non-OECD nations.

Occurs when non-OECD nations are unable to retain their top local researchers - as scientists study abroad and cannot return home to find career jobs in their disciplines, there is less infrastructure and resources to support research, or high bureaucracy that restricts research activities. This can lead to "brain drain," or the loss of local talent to foreign institutions.

Women often take on the caretaking responsibility at home as the culture norms and infrastructure have not shifted enough to support working women (i.e., more flexible working hours, increased resources for childcare).

\section{Examples in coral reef science}

A majority of coral reef research occurs in non-OECD nations that are often funded by OECD nations. Research teams are led by foreigners, and local researchers are often tasked with field assistant roles and setting up logistics, without having an opportunity to fully engage in the research design and analysis, thus warranting authorship. Level of effort may be the same but the value of the effort differs.

There is often a lack of research engagement by international coral reef researchers from OECD nations working with local experts that do not have the same academic credentials. Many coral reef research papers will interpret findings and provide recommendations without input from local knowledge or understanding of local social-ecological context. In STEM, numerous studies have shown that men author a much higher rate of invited publications (i.e., comments or views) - which has cascading effects on who are positioned to be thought leaders and experts in the field (Holman et al., 2018). While not specific to coral reefs, this pattern is likely to remain the same.

Prevalent in coral reef science because of the high concentration of reefs in non-OECD nations. This contributes to "parachute science" where researchers from OECD nations fund and lead international research - while much of the non-OECD nations are primarily focused in-country. This can also limit opportunities for researchers from non-OECD nations to partake in regional and international collaborations or simply lead their own science. In addition, this also leads to OECD nations often setting the research agenda and priorities in non-OECD nations.

Many critical studies in coral reef research do not get formally published due to many barriers. For example, local researchers in Latin America have carried out a high concentration of coral reef restoration studies in their region. However, it was increasingly apparent that much of the findings were not "being published," slowing down critical knowledge transfer. This issue led to a coral reef restoration review paper developed to increase awareness of the research and harness collective expertise of researchers who might not otherwise publish in a peer-reviewed journal (Bayraktarov et al., 2020).

Prevalent in coral reef science where much wealthier countries (i.e., Australia, United States) have access to funds for international research in non-OECD nations. There is little opportunity for local researchers from non-OECD nations to lead international collaborations or have access to those same opportunities to promote learning, career development, and execute high impact research. There is also a large education gap between OECD and non-OECD nations, with smaller proportions of the population moving on to higher levels of formal education, as they often enter the workforce earlier. Thus a barrier exists to even "enter" the scientific community. In the fisheries field, there is a "leaky pipeline" in career progression from graduate programs to more senior positions - as the graduate diversity pool is far more diverse than the more senior scholarly pool of researchers (Arismendi and Penaluna, 2016). This has been further exacerbated by COVID-19, where there are already indications that women's research production has declined (Vincent-Lamarre et al., 2020) as they have taken on more of the caretaking responsibilities. In coral reef science, where much of the work is field-based, this can also limit opportunities. 
TABLE 1 | (Continued)

\begin{tabular}{|c|c|c|}
\hline Issue & Description & Examples in coral reef science \\
\hline Toxic research culture & $\begin{array}{l}\text { Serious behavioral issues of condescension, bullying, } \\
\text { harassment, and toxicity that leads to hidden labor (above) and } \\
\text { dropout (e.g., Macdonald, 2020; Woolston, 2020). Both } \\
\text { individuals and institutions are responsible for this continued } \\
\text { culture. }\end{array}$ & $\begin{array}{l}\text { Coral reef research is particularly vulnerable to this negative } \\
\text { culture that persists, as much of this work is field based (Clancy } \\
\text { et al., 2014) and faces many of the same issues mentioned in } \\
\text { the recent paper (Macdonald, 2020) that discusses the "dark } \\
\text { side" of being a female shark researcher. The "power" dynamic } \\
\text { is prevalent in research and can impact international } \\
\text { collaborations - particularly the OECD vs. non-OECD } \\
\text { relationship-as foreign researchers often wield the power as } \\
\text { they are controlling the funding that creates an unhealthy } \\
\text { culture and leads to exploitation of local researchers. These } \\
\text { unhealthy power relationships can quickly lead to resentment } \\
\text { toward external scientists. }\end{array}$ \\
\hline
\end{tabular}

the existing disconnect between geographies where coral reef biodiversity is concentrated, where field work occurs, and where authors are presumably located and trained (Figure 2). Most collaborations are dominated by authors based in OECD nations conducting research in non-OECD nations (Figure 1 and Supplementary Figure 3). Our findings mirror broader trends in ecology, evolution, and marine science (8), though conservation lags behind other fields-Mammides et al. (2016) reveals the contribution of corresponding authors from low income countries in conservation literature has in fact declined over several decades. A recent survey of authorship from 13 leading journals in ecology, evolution, and conservation revealed that $86 \%$ of top-publishing authors were affiliated with 10 "Global North" countries while the remaining 32 countries, the majority of which were from the "Global South" were significantly underrepresented (Maas et al., 2021). This trend also applies to marine science: a review of over 150 marine systematic conservation planning papers found that $80 \%$ of publications were led by just five OECD nations, with Australia leading more plans overseas (often in non-OECD nations) than domestically (Álvarez-Romero et al., 2018). In a separate study, of the top 10 countries generating coral reef biodiversityrelated publications, only one (Indonesia) is a non-OECD nation (Stefanoudis et al., 2021). While efforts to move away from parachute science practices have been gradually improving since the 1990s, these findings suggest that they continue to persist (Stefanoudis et al., 2021).

These patterns in geographic representation are symptomatic of underlying systemic issues. In particular, economic inequalities have led to disparity in available research funding as well as job opportunities and career development (Table 1; Harris, 2004; The Royal Society, 2011; van Helden, 2012; Brito-Millán et al., 2019). Many researchers in non-OECD nations often obtain graduate degrees in OECD nations (Altbach, 2007), but do not return to their country of origin as there are often fewer opportunities for research careers at home-often referred to as "brain drain" (Docquier et al., 2007). Other systemic issues include biases and stereotypes, pervasive in coral reef science-where local and traditional knowledge and "western" science are not valued equally. In addition, local experts often perform "hidden labor" and are tasked with roles that are not often valued or deemed worthy of authorship (e.g., relationship development, research permits and permissions, logistics for data collection, data entry, historical knowledge), where the roles may be labor intensive (e.g., data collection), but not given the opportunity to meaningfully engage in research development and outcomes, including scientific publications; it is also common for visiting researchers to not share results or maintain relationships with the community after data collection. Other barriers relate to flaws in the academic publication system (particularly for international peer reviewers) that also cater toward English speakers, name discrimination (where biases exist toward AngloEuropean names), and prohibitively high publication costs (Pai, 2020). While we only examined publications from 10 high impact, global journals, we recognize we likely missed a significant portion of researchers who are effectively unable to publish in these outlets and may instead publish in the many nonEnglish national or regional marine science journals (Pai, 2020). At the same time, the 10 journals also have disproportionate influence on global coral reef research, and our findings reveal the voices of authors from non-OECD nations continue to be dramatically outnumbered by those from OECD nations.

Our results also reveal a persistent gender gap in authorship in coral reef sciences, with little progress made over the last decade. Across 16 years and 1,677 studies, authors who are men continue to dominate the publishing landscape, particularly in the senior author position. Our findings, which highlight the persistent gender gap in coral reef science, also identify a slow trajectory in closing that gap. If this trend continues at the current rate, it will take more than two decades to achieve more balanced representation $(\sim 50 \%)$ in authorship. This finding is mirrored more broadly across Science, Technology, Engineering, and Mathematics (STEM) disciplines, where women are found to be both underrepresented in prestigious STEM journals, with minimal change from 2006 to 2016. And while women were responsible for around 33\% first author positions, just $18 \%$ were in the last position (Bendels et al., 2018). Other studies examining authorship in ecological journals found little change in 13 years, with authorship by women around 29\% (Whelan and Schimel, 2019). Furthermore, a comprehensive study tracking the toppublishing authors from 1945 to 2019 associated with articles in the ecology, evolution, and conservation fields found that only $11 \%$ were women (Maas et al., 2021). Our findings amidst this body of evidence reiterates that progress remains slow despite 
the issue being well-documented and the increasing calls to address these issues.

The disparity in gender representation in science is tied to systemic issues and inequalities ranging from subtle biases, microaggressions, and toxic workplace environments where raising evidence of diversity issues or discrimination can be perceived as an attack to more privileged (i.e., older, white men), to discouragement or limited access to higher education, unequal access to healthcare and financial independence, and differential family roles and expectations (Table 1; O'Brien and Hapgood, 2012; Silbiger and Stubler, 2019). These can lead to real consequences for underrepresented backgroundssuch as those from certain racial or ethnic groups, national origins, or women-including drop out or stagnation in career development, as most STEM fields report that entry representation is near equal but that diversity decreases with each stage of career progression (Pico et al., 2020). In addition to publication bias, these issues also limit academic success and professional advancement. The continued use of publication metrics as a leading indicator of success for awards and promotion has implications in how women are perceived and has repercussions in leadership roles, from invited reviews in top journals, promotions, media requests, and invited speaking events (e.g., Holliday et al., 2014). For example, women are significantly underrepresented as speakers at coral reef conferences (e.g., Andradi-Brown et al., 2020); prior to 2021, only $19 \%$ of plenary speakers at the past four International Coral Reef Symposium have been women. There have been improvements in building better environments for women in the sciences, but the impacts of COVID-19 have undone much of it and revealed where significant weaknesses in research infrastructure and culture continue to disproportionately affect female scientists who often bear a disproportionate responsibility for family care (Kramer, 2020; Vincent-Lamarre et al., 2020).

The patterns and trends on who has the opportunities and resources to engage in scientific research is deeply rooted in the legacies of colonialism and global economic development (Brockington, 2002). Our findings provide quantitative evidence that colonial heritage and patriarchal societies present real and contemporary challenges facing coral reef science. Lack of geographic and gender representation in coral reef science is particularly detrimental as coral reef research increasingly aims to inform marine conservation and sustainability actions. By limiting perspectives in coral reef science, this slows innovation and research and for coral reefs, like many ecosystems, time is running out to find and implement solutions with increasing global and local threats (O'Hara et al., 2021). Degradation of coral reefs and coastal ecosystems have global repercussions, but the direct and immediate consequences are most intensely experienced by local communities in primarily non-OECD nations (Pendleton et al., 2016). When coral reef science is dominated by researchers external to these communities, there is significant risk of designing and implementing "solutions" based on science that may not achieve desired impacts or may have unintended negative consequences, particularly for those communities and groups already marginalized-mostly often women, Indigenous Peoples, and the rural poor (Baker et al.,
2019). Local scientists are likely to have greater success in ensuring the results from research are used in the formation of new policies and decision-making required to conserve reefs in non-OECD nations. Women in particular are leading much of the on-ground efforts in tackling social and ecological issues in coral reefs (Kleiber et al., 2015; Davis and Silver, 2019) but are still poorly represented in coral reef science. Research that intends to address the complexity of issues in coral reef science and conservation will need diverse perspectives to be effective for both reefs and the people who depend on them.

The intention of this study aims to be broad-in both the temporal and spatial at which we aim to characterize these two dimensions of diversity. We recognize that diversity is a multidimensional concept, one that does not neatly divide into categories-particularly in terms of gender identity. As such, the measures we use are heuristic. In coral reef science, individuals often will move from institution to institution throughout their education and career-often in different countries-thus institutional affiliation does not fully represent ethnic, racial, not national identity-and should be interpreted as a measure of geographic diversity of institutions. Furthermore, based on information available, our gender analysis focuses on "men" and "women", however, we recognize that gender exists on a spectrum and to the best extent of our ability, categorized gender based on publicly available information. We recognize that the way in which we have characterized these two dimensions of diversity does not encapsulate the full spectrum of how individuals or groups may identify, however, given the coarse resolution of publicly available information, these relatively simple metrics were the most appropriate analytical approach for exploring bibliometric trends within the scope of this study. Future work to investigate the full spectrum of diversity and identity can use more in-depth approaches, such as interviews and case studies, to better understand trends and drivers at finer scales.

\section{Recommendations}

Our results suggest that ongoing efforts to address the geographic and gender disparity that exists in coral reef research are not going far enough or moving fast enough. The science community needs to address deeply embedded institutional and cultural issues and commit to increased intentional action and accountability to accelerate positive tangible change. Here, we make three broad recommendations for the science community to proactively address the issues identified in this paper: (1) foster increased geographic representation in authorship and increase representation of authors from countries in which research is undertaken (Chambers et al., 2021); (2) improve gender representation in research teams and leadership (Fox et al., 2018; Potvin et al., 2018); and (3) directly address historical and institutional harm, while cultivating a culture of equity, diversity, inclusion, and justice in research institutions through measurable and concrete actions (Kalev and Dobbin, 2016).

First, fostering increased geographic representation in authorship requires fundamental changes to both research approaches and funding structures. Research that incentivizes engagement with in-country scientists, practitioners, and other actors through collaborative or knowledge co-production 
research processes should be emphasized as they "complement one another" and result in the "potential to effectively use all relevant knowledge" (Abram et al., 2019). Thus, researchers need to invest in creating meaningful and long-term partnerships with local organizations (including universities, government and non-government organizations, community groups) and engage local collaborators as co-designers, co-implementers, and coauthors of research outputs (Baker et al., 2019; Chin et al., 2019). The latter in these partnerships will require research leaders and institutions to tailor their engagement strategies for obtaining feedback and input of the co-authors involved. Scientific journals also have a critical role to play in ensuring representation of in-country scientists and other actors as authors and taking actions such as making language editing and/or translation more readily available, incorporating diverse co-authorship as a consideration in peer-review, and more accessible publication cost. Additionally, fostering geographic diversity in authorship and building locally led research will require a fundamental shift in how research funding is shared and allocated.

To share the rewards and build local capacity, we recommend that funding agencies and organizations: (a) require that research projects driven by foreign research teams involve equitable sharing of funding with local research groups (Hind et al., 2015); (b) increase allocations of funding directly to local researchers in non-OECD nations to carry out their own projects (Hind et al., 2015); (c) recognize and value research efforts that weave together different forms of knowledge (Alexander et al., 2011; Mackey and Claudie, 2015); (d) include local experts in co-design of research (Stefanoudis et al., 2021); and (e) allocate funding for mentorship/training to address the significant education gap between non-OECD and OECD nations, or language barriers (Hind et al., 2015; Chin et al., 2019).

Second, concerted effort is needed to reduce gender disparities, and underrepresentation in research teams, coauthor lists, and leadership positions. Bias toward women (i.e., perceived expertise or competencies) can seriously undermine gender representation in research and publication (Committee on Increasing the Number of Women in Science, Technology, Engineering, Mathematics, and Medicine (STEMM), 2020). Thus, the underlying factors that shape the composition of research groups and authorship is something that individual researchers and teams must continually reflect on and address. For example, the limited number of women last authors on papers suggests that they continue to be underrepresented in the academy and that granting agencies and research funders should pay greater attention to and be more accountable in recruiting, retaining, and funding women-led research projects and groups (Hewlett et al., 2008; Smith et al., 2017; Fox et al., 2018). There are direct actions to address publication challenges (e.g., more training and accountability of editors, double-blind peer-review, more diverse editor groups, inclusive gender practices such as additional fields in gender drop down (Budden et al., 2008; Fox et al., 2018; Graves et al., 2019). However, addressing underlying issues will require broader and more systemic efforts-for example, shifting workplace and work culture to be more supportive of non-work responsibilities, from family care to managing the household; and improving transparency and fairness of hiring and evaluation practices. Also important to recognize that while non-binary authors and those with other gender identities (transgender men and women) face many of the same challenges, they are often compounded.

Neocolonial (or globalization Boisselle, 2016) research practices (Table 1), lack of diversity, and toxic research cultures (e.g., condescension, bullying, and harassment; Howe-Walsh and Turnbull, 2014) are deeply ingrained and persistent in the sciences. Addressing these issues requires a long term vision and multi-pronged approach, which could start by establishing compensated DEI committees or working groups to identify specific areas for improvement and accountability, ${ }^{2}$ institutionalizing training by professionals in DEI for graduate students, postdocs, and faculty, and requiring up-to-date training in key ingredients of collaborative practices, knowledge co-production, anti-racism initiatives (Schell et al., 2020), and decolonial feminist research methods (Brito-Millán et al., 2019). Also key are: a code of conduct that explicitly states standards, confidential reporting, and repercussions; the inclusion of DEI work and mentorship metrics in hiring and tenure; and a commitment to increasing and maintaining diverse hires at all institutional levels. Together, these kinds of initiatives would improve institutional understanding and accountability of DEI issues (including the role of unconscious biases) and encourage personal introspection and goal setting around inclusion. Lack of accountability allows toxic behavior to persist which leads to many women and other underrepresented groups leaving research and academia (Howe-Walsh and Turnbull, 2014). Given the significant power that institutional actors (universities, research institutes, journal editorial boards, field stations, funding agencies) and science leaders hold in the science community, they must establish a precedent to make diversity inclusiveness policies explicit and develop clear action plans, targets, and monitoring and evaluation toward their implementation (Kalev and Dobbin, 2016).

It is currently 2021, and the lack of representation in coral reef science continues to persists with the pace of change too slow to achieve balanced representation anytime soon. We (the authors) realize that fixing the problem goes beyond the scientific community given these trends are reflective of much broaderscale social processes, norms, and histories (i.e., patriarchy, colonization, uneven geographical development). However, the science community-both individually and institutionallyhas a significant role to play in bringing about real social change, from shifting the culture in funding, to increasing engagement of international researchers with local experts. And while authorship is just one symptom of systemic issues in research, advocating for more inclusive research practices can contribute toward progress for broader DEI goals. Individuals and institutions need to collectively take action and not rely so heavily on underrepresented groups who disproportionately allocate time and resources to addressing these systemic issues (Jimenez et al., 2019). Global challenges are big for coral reefs, but

\footnotetext{
${ }^{2}$ https://www.coralcoe.org.au/gender-equity/jedi
} 
with the right set of actions, we can work toward more innovative, inclusive, science-based solutions.

\section{DATA AVAILABILITY STATEMENT}

Summary statistics for this study were calculated in $\mathrm{R}$ and the data cleaning and analysis scripts can be found on github (https: //github.com/scheng87/coralreef).

\section{AUTHOR CONTRIBUTIONS}

GNA and SHC: conception, data analysis, and supervision. GNA, SHC, DAA-B, SKB, MDB, SJC, DG, E, EG, GGG, VH, RJ, SM, SLM, NAM, NS, LV, HV, AV, ASW, and AW: data acquisition. GNA, SHC, DAA-B, SKB, MDB, SJC, DG, E, EG, GGG, VH, RJ, SM, SLM, NAM, NS, LV, HV, AV, ASW, AW, NJB, ESD, EVK, MON, and SBM: data interpretation and drafting of the work. All authors contributed to the article and approved the submitted version.

\section{REFERENCES}

Abram, N., Gattuso, J. P., Prakash, A., Cheng, L., Chidichimo, M. P., Crate, S., et al. (2019). Framing and Context of the Report. IPCC Special Report on the Ocean and Cryosphere in a Changing Climate. Geneva: IPCC.

Adenle, A. A., Stevens, C., and Bridgewater, P. (2015). Global conservation and management of biodiversity in developing countries: an opportunity for a new approach. Environ. Sci. Policy 45, 104-108. doi: 10.1016/j.envsci.2014.10.002

Ahmadia, G. (2018). Recruit young scientists and local talent to safeguard coral reefs. Nature 557, 492-492. doi: 10.1038/d41586-018-05221-x

Alexander, C., Bynum, N., Johnson, E., King, U., Mustonen, T., Neofotis, P., et al. (2011). Linking indigenous and scientific knowledge of climate change. BioScience 61, 477-484. doi: 10.1525/bio.2011.61.6.10

Altbach, P. G. (2007). "Globalization and the university: realities in an unequal world," in International Handbook of Higher Education. Springer International Handbooks of Education, eds J. J. F. Forest, and P. G. Altbach (Dordrecht: Springer), 18. doi: 10.1007/978-1-4020-4012-2_8

Álvarez-Romero, J. G., Mills, M., Adams, V. M., Gurney, G. G., Pressey, R. L., Weeks, R., et al. (2018). Research advances and gaps in marine planning: towards a global database in systematic conservation planning. Biol. Conserv. 227, 369-382. doi: 10.1016/j.biocon.2018.06.027

Andradi-Brown, D. A., Banaszak, A. T., Frazer, T. K., Gilchrist, H., Harborne, A. R., Head, C. E. I., et al. (2020). Editorial: coral reefs in the anthropocene reflecting on 20 years of reef conservation UK. Front. Mar. Sci. 7:364. doi: 10.3389/fmars.2020.00364

Arismendi, I., and Penaluna, B. E. (2016). Examining diversity inequities in fisheries science: a call to action. BioScience 66, 584-591. doi: 10.1093/biosci/ biw041

Baker, K., Eichhorn, M. P., and Griffiths, M. (2019). Decolonizing field ecology. Biotropica 51, 288-292. doi: 10.1111/btp.12663

Bayraktarov, E., Banaszak, A. T., Montoya Maya, P., Kleypas, J., Arias-González, J. E., Blanco, M., et al. (2020). Coral reef restoration efforts in latin american countries and territories. PLoS One 15:e228477. doi: 10.1371/journal.pone. 0228477

Bendels, M. H. K., Müller, R., Brueggmann, D., and Groneberg, D. A. (2018). Gender disparities in high-quality research revealed by nature index journals.” Edited by sergi lozano. PLoS One 13:e0189136. doi: 10.1371/journal.pone. 0189136

Bennett, N. J. (2018). Navigating a just and inclusive path towards sustainable oceans. Mar. Policy 97, 139-146. doi: 10.1016/j.marpol.2018.06.001

Boisselle, L. N. (2016). Decolonizing science and science education in a postcolonial space (Trinidad, a developing caribbean nation, illustrates). SAGE Open 6:215824401663525. doi: 10.1177/2158244016635257

\section{ACKNOWLEDGMENTS}

We acknowledge the contributions of the many unrecognized and undervalued individuals in coral reef research whose efforts have made it possible for the field to progress. These scientists have collected data, translated across languages, coordinated field work, welcomed foreign visitors to their countries, shared ideas, trained and mentored students, become friends, inspired, and built the foundation for the discipline we know today. We acknowledge the work of all coral reef scientists who continue day after day to pursue equity, inclusion, and justice in the field and for their colleagues and themselves.

\section{SUPPLEMENTARY MATERIAL}

The Supplementary Material for this article can be found online at: https://www.frontiersin.org/articles/10.3389/fmars. 2021.731037/full\#supplementary-material

Bray, N. (2020). Insight into citation bias. Nat. Rev. Neurosci. 21, 452-452. doi: 10.1038/s41583-020-0357-4

Brito-Millán, M., Cheng, A., Quintanilla, L., Harrison, E., Sugla, R., Martinez, A., et al. (2019). No comemos baterías: solidarity science against false climate change solutions. Sci. People 22:33.

Brockington, D. (2002). Fortress Conservation: The Preservation of the Mkomazi Game Reserve, Tanzania. African Issues. Bloomington, IND: Indiana University Press.

Brown, M., Cheng, S., and Tolisano, J. (2019). From Threat to Solution: Rethinking the Role of Communities in Nature Conservation (Commentary)." Mongabay News. Available online at: https://news.mongabay.com/2019/09/rethinkingthe-role-of-communities-in-nature-conservation-from-threat-to-solutioncommentary/ (Accessed September 24, 2019).

Budden, A. E., Tregenza, T., Aarssen, L. W., Koricheva, J., Leimu, R., and Lortie, C. J. (2008). Double-blind review favours increased representation of female authors. Trends Ecol. Evol. 23, 4-6. doi: 10.1016/j.tree.2007.07.008

Chambers, J. M., Wyborn, C., Ryan, M. E., Reid, R. S., Riechers, M., Serban, A., et al. (2021). Six modes of co-production for sustainability. Nat. Sustain. 1-14. doi: 10.1038/s41893-021-00755-x

Chaudhury, A., and Colla, S. (2020). Next steps in dismantling discrimination: lessons from ecology and conservation science. Conserv. Lett. 14:e12774. doi: $10.1111 /$ conl.12774

Chin, A., Baje, L., Donaldson, T., Gerhardt, K., Jabado, R. W., Kyne, P. M., et al. (2019). The scientist abroad: maximising research impact and effectiveness when working as a visiting scientist. Biol. Conserv. 238:108231. doi: 10.1016/ j.biocon.2019.108231

Clancy, K. B. H., Nelson, R. G., Rutherford, J. N., and Hinde, K. (2014). Survey of academic field experiences (SAFE): trainees report harassment and assault. PLoS One 9:e102172. doi: 10.1371/journal.pone.0102172

Committee on Increasing the Number of Women in Science, Technology, Engineering, Mathematics, and Medicine (STEMM), Committee on Women in Science, Engineering, and Medicine, Policy and Global Affairs, and National Academies of Sciences, Engineering, and Medicine (2020). Promising Practices for Addressing the Underrepresentation of Women in Science, Engineering, and Medicine: Opening Doors, eds R. Colwell, A. Bear, and A. Helman (Washington, D.C: National Academies Press), doi: 10.17226/25585

Conti, A., and Visentin, F. (2015). Science and engineering Ph.D. Students' career outcomes, by gender. PLoS One 10:e0133177. doi: 10.1371/journal.pone. 0133177

Csardi, G., and Nepusz, T. (2006). The igraph software package for complex network research. InterJournal Complex Syst. 1695, 1-9.

Davis, R., and Silver, M. (2019). No Sex For Fish: How Women In A Fishing Village Are Fighting For Power. NPR.Org. 2019. Available online at: 
https://www.npr.org/sections/goatsandsoda/2019/12/26/789129312/no-sexfor-fish-how-women-in-a-fishing-village-are-fighting-for-power (accessed February 2, 2021).

de Vos, A. (2020). The Problem of 'Colonial Science'. Conservation Projects in the Developing World Should Invest in Local Scientific Talent and Infrastructure. Scientific American, 2020. Available online at: https://www.scientificamerican. com/article/the-problem-of-colonial-science/ (accessed September 3, 2021).

Docquier, F., Lohest, O., and Marfouk, A. (2007). Brain drain in developing countries. World Bank Econ. Rev. 21, 193-218. doi: 10.1093/wber/lhm008

Eisenstein, C. (2018). Climate: A New Story. Berkeley, CA: North Atlantic Books.

Fantom, N., Khokhar, T., and Purdie, E. (2016). The 2016 Edition of World Development Indicators Is out: Three Features You Won't Want to Miss. World Bank Blogs (blog). 2016. Available online at: https://blogs.worldbank.org/opendata/2016-edition-world-developmentindicators-out-three-features-you-won-t-want-miss (accessed March 21, 2021).

Fisher, R., Radford, B. T., Knowlton, N., Brainard, R. E., Michaelis, F. B., and Caley, J. M. (2011). Global mismatch between research effort and conservation needs of tropical coral reefs: global distribution of coral reef research. Conserv. Let. 4, 64-72. doi: 10.1111/j.1755-263X.2010.00146.x

Fox, C. W., Ritchey, J. P., and Paine, C. T. (2018). Patterns of authorship in ecology and evolution: first, last, and corresponding authorship vary with gender and geography. Ecol. Evol. 8, 11492-11507. doi: 10.1002/ece3.4584

Freeman, R. B., and Huang, W. (2015). Collaborating with people like me: ethnic coauthorship within the United States. J. Labor Econ. 33, S289-S318. doi: 10. $1086 / 678973$

Graves, A., Rowell, A., and Hunsicker, E. (2019). An Impact Evaluation Of The Athena SWAN Charter. Newcastle upon Tyne: Ortus Economic Research.

Handley, I. M., Brown, E. R., Moss-Racusin, C. A., and Smith, J. L. (2015). Quality of evidence revealing subtle gender biases in science is in the eye of the beholder. Proc. Natl. Acad. Sci. U.S.A. 112, 13201-13206. doi: 10.1073/pnas. 1510649112

Harris, E. (2004). Building scientific capacity in developing countries: simply transferring knowledge and instrumentation is not enough to help developing countries build their own research base. Such efforts must be tied to national and local needs to create trust and services for society in the long term. EMBO Rep. 5, 7-11. doi: 10.1038/sj.embor.7400058

Hewlett, S. A., Buck Luck, C., Servon, L. J., Serbin, L., Shiller, P., Sosnovich, E., et al. (2008). The Athena Factor: Reversing the Brain Drain in Science, Engineering, and Technology." Harvard Business Review Research Report. New York, NY: Center for Work-Life Policy.

Hind, E. J., Alexander, S. M., Green, S. J., Kritzer, J. P., Sweet, M. J., Johnson, A. E., et al. (2015). Fostering effective international collaboration for marine science in small island states. Front. Mar. Sci. 2:86. doi: 10.3389/fmars.2015.00086

Hofstra, B., Kulkarni, V. V., Munoz-Najar Galvez, S., He, B., Jurafsky, D., and McFarland, D. A. (2020). The diversity-innovation paradox in science. Proc. Natl. Acad. Sci. U.S.A. 117, 9284-9291. doi: 10.1073/pnas.1915378117

Holliday, E. B., Jagsi, R., Wilson, L. D., Choi, M., Thomas, C. R., and Fuller, C. D. (2014). Gender differences in publication productivity, academic position, career duration, and funding among U.S. academic radiation oncology faculty. Acad. Med. 89, 767-773. doi: 10.1097/ACM.0000000000000229

Holman, L., Stuart-Fox, D., and Hauser, C. E. (2018). The gender gap in science: how long until women are equally represented?" Edited by cassidy sugimoto. PLoS Biol. 16:e2004956. doi: 10.1371/journal.pbio.2004956

Howe-Walsh, L., and Turnbull, S. (2014). Barriers to women leaders in academia: tales from science and technology. Stud. High. Educ. 41, 415-428. doi: 10.1080/ 03075079.2014.929102

Huang, J., Gates, A. J., Sinatra, R., and Barabási, A. (2020). Historical comparison of gender inequality in scientific careers across countries and disciplines. Proc. Natl. Acad. Sci. U.S.A. 117, 4609-4616. doi: 10.1073/pnas.1914221117

Jimenez, M. F., Laverty, T. M., Bombaci, S. P., Wilkins, K., Bennett, D. E., and Pejchar, L. (2019). "Underrepresented fculty play a disproportionate role in advancing diversity and inclusion. Nat. Ecol. Evol. 3, 1030-1033. doi: 10.1038/ s41559-019-0911-5

Kalev, F., and Dobbin, A. (2016). Spotlight on Building a Diverse OrganisationWhy Diversity Programs Fail and What Works Better. Harvard Business Review. Available online at: https://stratserv.co/wp-content/uploads/2020/08/ Why-Diversity-Programs-Fail.pdf (accessed Augest 17, 2021).
Kleiber, D., Harris, L. M., and Vincent, A. C. J. (2015). Gender and small-scale fisheries: a case for counting women and beyond. Fish Fish. 16, 547-562. doi: $10.1111 /$ faf.12075

Kramer, J. (2020). Women in Science May Suffer Lasting Career Damage from COVID-19. Scientific American, 2020. Available online at: https://www.scientificamerican.com/article/women-in-science-may-sufferlasting-career-damage-from-covid-19/ (accessed February 2, 2021).

Larivière, V., Ni, C., Gingras, Y., Cronin, B., and Sugimoto, C. R. (2013). Bibliometrics: global gender disparities in science. Nat. News 504:211. doi: $10.1038 / 504211 \mathrm{a}$

Maas, B., Pakeman, R. J., Godet, L., Smith, L., Devictor, V., and Primack, R. (2021). Women and global south strikingly underrepresented among top-publishing ecologists. Conserv. Lett. 14:e12797. doi: 10.1111/conl.12797

Macdonald, C. (2020). "The Dark Side of Being a Female Shark Researcher." Scientific American. Available online at: https://www.scientificamerican.com/ article/the-dark-side-of-being-a-female-shark-researcher/ (accessed August $10,2020)$.

Mackey, B., and Claudie, D. (2015). Points of contact: integrating traditional and scientific knowledge for biocultural conservation. Environ. Ethics 37, 341-357. doi: 10.5840/enviroethics201537332

Mammides, C., Goodale, U. M., Corlett, R. T., Chen, J., Bawa, K. S., Hariya, H., et al. (2016). Increasing geographic diversity in the international conservation literature: a stalled process? Biol.l Conserv. 198, 78-83. doi: 10.1016/j.biocon. 2016.03.030

Martin, D. (2012). Two-eyed seeing: a framework for understanding indigenous and non-indigenous approaches to indigenous health research. Can. J. Nurs. Res. 44, 20-43.

Meijaard, E., Cardillo, M., Meijaard, E. M., and Possingham, H. P. (2015). Geographic bias in citation rates of conservation research: geographic bias in citation rates. Conserv. Biol. 29, 920-925. doi: 10.1111/cobi.12489

Melles, S. J., Scarpone, C., Julien, A., Robertson, J., Bello Levieva, J., Carrier, C., et al. (2019). Diversity of practitioners publishing in five leading international journals of applied ecology and conservation biology, 1987-2015 relative to global biodiversity hotspots. Écoscience 26, 323-340. doi: 10.1080/11956860. 2019.1645565

Miller, D. C., Agrawal, A., and Timmons Roberts, J. (2013). Biodiversity, governance, and the allocation of international aid for conservation. Conserv. Lett. 6, 12-20. doi: 10.1111/j.1755-263X.2012.00270.x

Nuñez, M. A., and Amano, T. (2021). Monolingual searches can limit and bias results in global literature reviews. Nat. Ecol. Evol. 5, 264-264. doi: 10.1038/ s41559-020-01369-w

O'Brien, K. R., and Hapgood, K. P. (2012). The academic jungle: ecosystem modelling reveals why women are driven out of research. Oikos 121, 999-1004. doi: 10.1111/j.1600-0706.2012.20601.x

O’Hara, C. C., Frazier, M., and Halpern, B. S. (2021). At-risk marine biodiversity faces extensive, expanding, and intensifying human impacts. Science 372, 84-87. doi: $10.1126 /$ science.abe6731

OECD (2020). Developing Countries and the Ocean Economy. In: OECD Work in Support of a Sustainable Ocean. Available online at: https://www.oecd.org/ ocean/OECD-work-in-support-of-a-sustainable-ocean.pdf (accessed April 19, 2021).

Pai, M. (2020). How Prestige Journals Remain Elite, Exclusive And Exclusionary. Forbes, 2020. Available inline at: https://www.forbes.com/sites/madhukarpai/ 2020/11/30/how-prestige-journals-remain-elite-exclusive-and-exclusionary/ ?sh=ab5c56b4d48f (accessed March 15, 2021).

Pendleton, L., Comte, A., Langdon, C., Ekstrom, J. A., Cooley, S. R., Suatoni, L., et al. (2016). Coral reefs and people in a high-CO2 world: where can science make a difference to people? PLoS One 11:e0164699. doi: 10.1371/journal.pone. 0164699

Pico, T., Bierman, P., Doyle, K., and Richardson, S. (2020). First authorship gender gap in the geosciences. Earth Space Sci. 7:e2020EA001203. doi: 10.1029/ 2020EA001203

Potvin, D. A., Burdfield-Steel, E., Potvin, J. M., and Heap, S. M. (2018). “Diversity begets diversity: a global perspective on gender equality in scientific society leadership. PLoS One 13:e0197280. doi: 10.1371/journal.pone.0197280

Purdy, J. (2015). Environmentalism's Racist History. The New Yorker. 2015. Available online at: https://www.newyorker.com/news/news-desk/ environmentalisms-racist-history (accessed February 2, 2021). 
Schell, C. J., Guy, C., Shelton, D. S., Campbell-Staton, S. C., Sealey, B. A., Lee, D. N., et al. (2020). Recreating wakanda by promoting black excellence in ecology and evolution. Nat. Ecol. Evol. 4, 1285-1287. doi: 10.1038/s41559-020-1266-7

Selig, E. R., Hole, D. G., Allison, E. H., Arkema, K. K., McKinnon, M. C., Chu, J., et al. (2018). Mapping global human dependence on marine ecosystems. Conserv. Lett. 12:e12617. doi: 10.1111/conl.12617

Silbiger, N. J., and Stubler, A. D. (2019). Unprofessional peer reviews disproportionately harm underrepresented groups in STEM. PeerJ 7:e8247. doi: $10.7717 /$ peerj. 8247

Smith, N. S., Côté, I. M., Martinez-Estevez, L., Hind-Ozan, E. J., Quiros, A. L., Johnson, N., et al. (2017). Diversity and inclusion in conservation: a proposal for a marine diversity network. Front. Mar. Sci. 4:234. doi: 10.3389/fmars.2017. 00234

Spalding, M., Brumbaugh, R. D., and Landis, E. (2016). Atlas of Ocean Wealth. Arlington, VA: The Nature Conservancy.

Stefanoudis, P. V., Licuanan, W. Y., Morrison, T. H., Talma, S., Veitayaki, J., and Woodall, L. C. (2021). Turning the tide of parachute science. Curr. Biol. 31, R184-R185. doi: 10.1016/j.cub.2021.01.029

Stuchtey, M., Vincent, A., Merkl, A., Bucher, M., Haugan, P., Lubchenco, J., et al. (2020). Ocean Solutions That Benefit People, Nature and the Economy. Washington, DC: World Resources Institute.

The Royal Society. (2011). Knowledge, Networks and Nations: Global Scientific Collaboration in the 21st Century. Policy Document 03/11. London: The Royal Society.

Tulloch, A. I. T. (2020). Improving sex and gender identity equity and inclusion at conservation and ecology conferences. Nat. Ecol. Evol. 4, 1311-1320. doi: 10.1038/s41559-020-1255-x

van Helden, P. (2012). The cost of research in developing countries. EMBO Rep. 13, 395-395. doi: 10.1038/embor.2012.43

Vernos, I. (2013). Quotas are questionable. Nature 495, 39-39. doi: 10.1038/ 495039 a

Vincent-Lamarre, P., Sugimoto, C. R., and Larivière, V. (2020). The Decline of Women's Research Production during the Coronavirus Pandemic. Nature Index.
Available online at: https://www.natureindex.com/news-blog/decline-womenscientist-research-publishing-production-coronavirus-pandemic (accessed April 19, 2021).

Waldron, A., Miller, D. C., Redding, D., Mooers, A., Kuhn, T. S., Nibbelink, N., et al. (2017). Reductions in global biodiversity loss predicted from conservation spending. Nature 551, 364-367. doi: 10.1038/nature24295

Whelan, A. M., and Schimel, D. S. (2019). Authorship and gender in ESA journals. Bull. Ecol. Soc. Am. 100:e01567. doi: 10.1002/bes2.1567

Woolston, C. (2020). Postdocs under pressure: 'can i even do this any more?' Nature 587, 689-692. doi: 10.1038/d41586-020-03235-y

World Bank (2021). World Bank Country and Lending Groups. Data (blog). Washington, DC: World Bank.

Conflict of Interest: The authors declare that the research was conducted in the absence of any commercial or financial relationships that could be construed as a potential conflict of interest.

Publisher's Note: All claims expressed in this article are solely those of the authors and do not necessarily represent those of their affiliated organizations, or those of the publisher, the editors and the reviewers. Any product that may be evaluated in this article, or claim that may be made by its manufacturer, is not guaranteed or endorsed by the publisher.

Copyright (c) 2021 Ahmadia, Cheng, Andradi-Brown, Baez, Barnes, Bennett, Campbell, Darling, Estradivari, Gill, Gress, Gurney, Horigue, Jakub, Kennedy, Mahajan, Mangubhai, Matsuda, Muthiga, Navarro, Santodomingo, Vallès, Veverka, Villagomez, Wenger and Wosu. This is an open-access article distributed under the terms of the Creative Commons Attribution License (CC BY). The use, distribution or reproduction in other forums is permitted, provided the original author(s) and the copyright owner(s) are credited and that the original publication in this journal is cited, in accordance with accepted academic practice. No use, distribution or reproduction is permitted which does not comply with these terms. 